followed by chapters on the examination of individual joints, including the cricoarytenoid joint. At the beginning of each chapter there is a valuable section on essential anatomy followed by sections on inspection, palpation, movement and range of motion, muscle testing, and finally any special tests, The British reader might have wished for a wider discussion on the assessment of disease activity and spinal movement and there is no mention of the Richie index. This book should be read by all rheumatologists in training and it should be available for reference in every department.

I. D. L. BREWIS

Piroxicam. Royal Society of Medicine International Congress and Symposium Series 1. Eds. W. M. O'Brien and E. H. Wiseman. Pp. 111. \$10.25. Academic Press: London. 1978.

There seems to be no end to the supply of new nonsteroidal anti-inflammatory drugs. There is also a steady increase in the number of journals in which papers about them may be concealed. It is therefore useful to bring together the current state of knowledge of a new compound in a readily accessible source. This volume provides lots of information about piroxicam, and although the story is clearly incomplete it looks interesting. The pharmacology and pharmacokinetics are well described. The latter predicts that piroxicam can be given once daily, and clinical data support this view. Clinical trials in a number of different conditions suggest that piroxicam is another useful anti-inflammatory.

E. C. HUSKISSON

Spinal Phlebography: Lumbar and Cervical Techniques. Eds. J. Theron and J. Moret. Pp. 165. DM 118. SpringerVerlag: Berlin. 1978.

Spinal phlebography is a relatively new radiological technique used for investigating vertebromedullary pathology. It has the advantage over myelography and radiculography of not requiring puncture of the subarachnoid space and seems a relatively harmless and almost painless procedure. However, the interpretation of the radiographic appearances of the epidural veins is highly skilled and demands special experience.

With various collaborators the authors have made detailed studies of the physiological and anatomical bases of the epidural venous system both in man and in animals. They then illustrate the techniques, problems, and results of phlebography of both the lumbar and cervical areas. The whole book is profusely and magnificently illustrated. Primarily it is directed at radiologists, but it will be of interest to all who have to deal with the diagnosis of lumbar and cervical conditions.

M. I. V. JAYSONO

\title{
Register of Events in Rheumatology: 1980-1
}

\section{October}

28-30

November

20-21

23-30

1981

April

3-4

30-1 May
NAIDEX '80

Heberden SocietyAGM and Oration

Queen Elizabeth Hall, London

II International

Seminar on the

Treatment of

Rheumatic Disease

Tel-Aviv, Israel
June

21-27
Paris

A complete list of rheumatological meetings in the UK is published in January and July of each year in the BLAR Newsletter, which is available from the Arthritis and Rheumatism Council, 8 Charing Cross Road, London WC2H 0HN.

\section{Note}

\section{Panhellenic Congress in Rheumatology}

Organised by the Hellenic Society of Rheumatology, this congress will be held on 27-29 November 1980 at Athens Hilton Hotel. Inquiries to Demetrios M Strouboulis, MD, 11 Pindarou Str, Athens 136, Greece. 